\title{
Management of Unilateral Fibro-epithelial Hyperplasia of Gingiva
}

\author{
Shilpa Ahuja, Kapil Gandhi, Ritika Malhotra, Tanvi Saxena, Rishabh Kapoor
}

Department of Pedodontics and Preventive Dentistry, Inderprastha Dental College and Hospital, Sahibabad, Ghaziabad-201010, Uttar Pradesh, India.

\section{Corresponding Author: \\ Dr. Shilpa Ahuja \\ Email: shilpaahuj@gmail.com \\ This is an Open Access article distributed under the terms of the Creative Commons Attribution License (creativecommons.org/ licenses/by/3.0).}

Received : May 8, 2017

Accepted : July 3,2017

Published : August 5, 2017

\begin{abstract}
Background: Fibro-epithelial hyperplasia, a histological variant of fibroma is a proliferative fibrous lesion of the gingival tissue that hinders function and aesthetics. Case Report: This article discusses an unusual case of unilateral fibro-epithelial hyperplasia in an eight year old Indian male child. The reason for the enlargement was local irritation caused by plaque and calculus. The resulting inflammatory gingival tissue was surgically excised following which conventional periodontal therapy was performed which significantly reduced the size of enlargement. Conclusion: Knowledge regarding the clinical presentation of most common oral lesions in children helps in early diagnosis and early management with minimal surgical intervention.
\end{abstract}

Keywords: Gingiva, Hyperplasia, Plaque, Calculi, Fibroma, Esthetics.

\section{Introduction}

Oral mucosa being constantly subjected to various stimuli manifests with a spectrum of disease which may be developmental, inflammatory, reactive or neoplastic [1]. These lesions may manifest as either generalized or localized [1,2]. Fibro-epithelial hyperplasia, a histological variant of fibroma is a proliferative fibrous lesion of the gingival tissue that hinders function and aesthetics. Clinically, this condition usually manifest as enlarged gingival tissues in a healthy mouth almost completely filling the interproximal spaces, beginning near the contact area and extending apically and laterally in a smooth curve.

The etiology of gingival enlargement may be either inflammatory, non-inflammatory or a combination of both [2]. Prolonged chronic inflammation of the gingival tissue is due to local irritations such as poor oral hygiene, accumulation of dental calculus resulting in enlargement of gingiva. This article addresses the treatment of a case of unusual inflammatory unilateral fibroepithelial hyperplasia.

\section{Case Report}

An eight year old Indian male child accompanied by his parents presented with a complaint of unilateral swelling of gingiva since four years. The swelling was accompanied with pain which was dull, progressive, throbbing and intermittent. He stopped chewing food from the affected side due to painful decayed teeth. The patient gave history of gradual enlargement of the gingiva with spontaneous bleeding. On general examination, the patient was moderately built and nourished. The reported medical and family histories were noncontributory.

The intraoral examination showed a diffuse, nodular enlargement of gingiva extending from lateral incisor to first molars on left side of both arches [Fig.1]. The teeth were partially visible as the gingival tissue was significantly overlapping them. The color of the gingiva appeared to be normal. It was firm and non-tender on palpation. Bleeding on probing was noted. Calculus deposits were seen on exposed tooth surfaces. Orthopantomograph was advised which revealed normal 
dentition with no radiographic evidence of any pathology [Fig.2]. However, the premolars on the affected side had erupted into the oral cavity suggesting early eruption due to local cause. From the clinical examination, a provisional diagnosis of inflammatory gingival enlargement was arrived at and the patient was subjected to a thorough medical examination which was normal. Patient was taken up for phase I periodontal therapy which included scaling and root planning. After a week patient was recalled for the surgical approach. External bevel gingivectomy procedure was planned quadrant wise in both upper and lower arches with one month interval between the two appointments.

The excised tissue was sent for histopathological examination. The examination revealed hyper-parakeratinised stratified squamous epithelium with underlying fibrous connective tissue. Connective tissue showed bundles of collagen fibers, coursing in an irregular pattern. Mild acute inflammatory infiltrate comprising polymorphonuclear leucocytes were noted. The histopathological features were suggestive of fibro-epithelial hyperplasia [Fig.3]. The patient was advised to maintain a scrupulous oral hygiene and was advised to come for regular checkup. The patient was reviewed after three months [Fig.4].

\section{Discussion}

Gingival enlargement, a common feature of gingival disease can be caused by various stimuli and hence treatment is based on the underlying cause and pathologic changes [3]. Usually local conditions such as poor oral hygiene, food impaction, or mouth breathing are the contributory factors for the condition. Inflammatory gingival hyperplasia results when gingival enlargement is accompanied by edema, vascular engorgement, and inflammatory cell infiltration. When the enlarged gingival tissue consists of dense fibrous tissue as a result of chronic inflammation, it is referred to as fibrotic gingival hyperplasia. The term "chronic hyperplastic gingivitis" often is referred to either processes $[2,4]$.

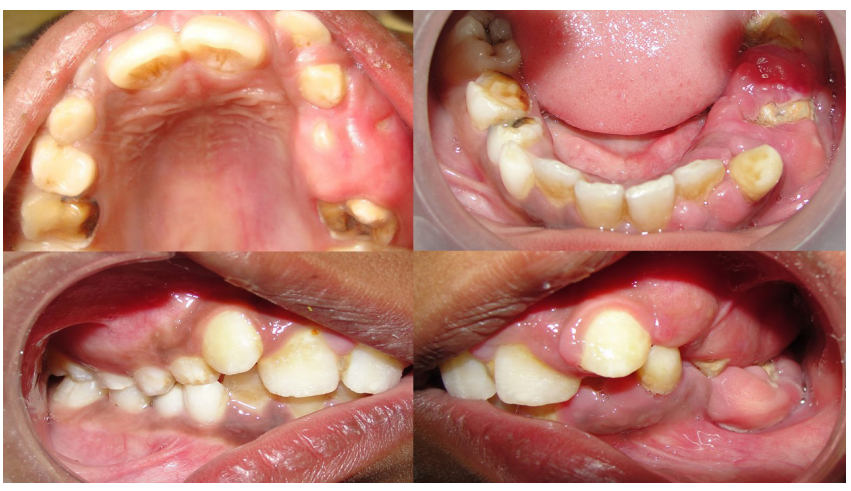

Fig.1: Intra-oral pre-operative photograph showing enlarged gingiva.

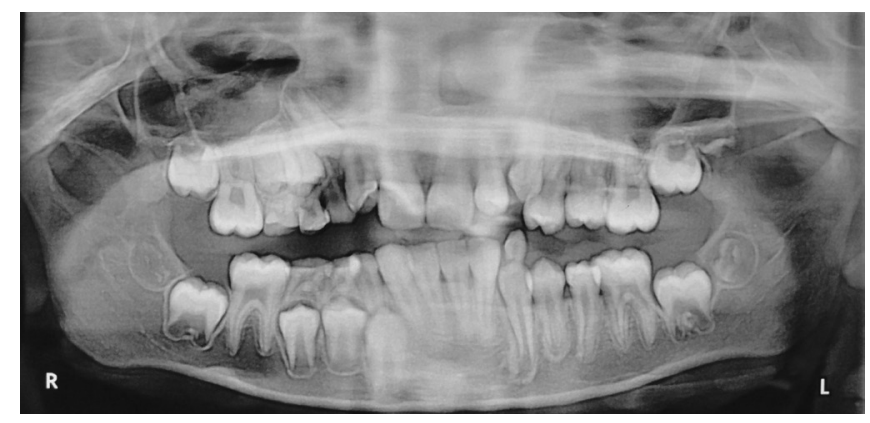

Fig.2: Orthopantomograph revealed normal dentition.

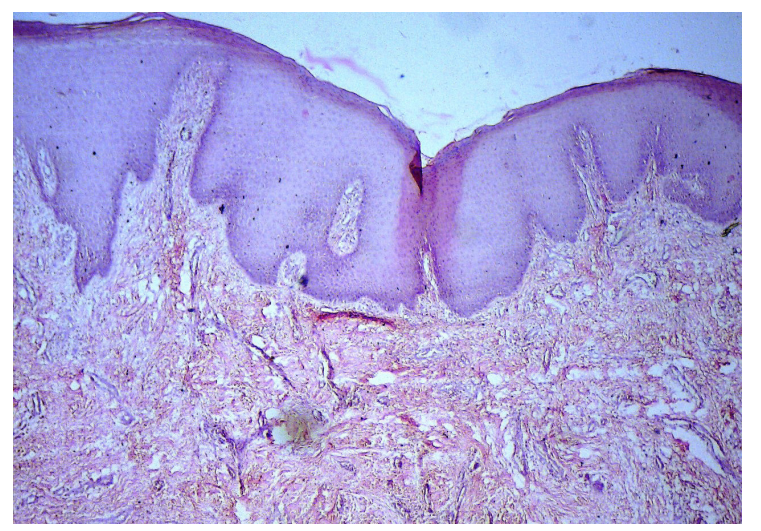

Fig.3: Histopathological features (×40, H\& E stain) showing fibro-epithelial hyperplasia.

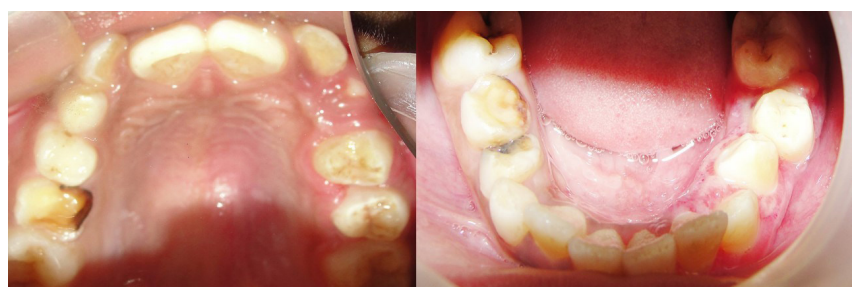

Fig.4: Intra-oral post-operative photograph of maxillary and mandibular arch. 
Fibro-epithelial hyperplasias are usually reactive/inflammatory conditions and result in variety of lesions named according to their clinical presentation. Pyogenic granuloma or fibrous epulis is named so because of the vascularity and presence of ulceration. These lesions arise mainly on gingiva, reflecting presence of inflammation in the interdental papillae being characteristic. Local predisposing factor like maligned teeth, improper or ill-fitting restorations or calculus which prevent removal of bacterial plaque and indirectly induced inflammation are commonly reported $[2,5,6]$. However, these conditions are considered selflimiting. As they interfere with form and function, their excision is warranted. A long standing hyperplastic lesion can turn neoplastic in the presence of chronic irritation [7].

In the present case, the plaque and calculus deposits on tooth surfaces could be the cause of chronic irritation of gingival tissues resulting in their proliferation. Clinically, the involved gingiva appeared to be firm without spontaneous bleeding. The chronic nature of the lesion resulted in the fibrotic nature of the gingiva. There are some reports that apart from local irritation, certain drugs can induce fibro-hyperplastic gingival over-growth. Six patients with gingival fibrous hyperplasia associated with cyclosporine A (CyA) therapy has been reported in the literature [8]. Arvio P reported gingival enlargement in patients with aspartyl glucosaminuria (AGU) [9].

Furthermore, the term fibro-epithelial hyperplasia needs to be differentiated from focal epithelial hyperplasia which is caused by human papilloma virus. In focal epithelial hyperplasia, all changes occur in the epithelial layer of the mucosa with virtually no alteration in the underlying connective tissue [10]. The histo-pathological features are distinct although considerable overlap still exists among these lesions.

\section{Conclusion}

A Pedodontist must have knowledge regarding the clinical presentation of most common oral lesions in children, which helps in early diagnosis and early management with minimal surgical intervention. Further studies are required with longer periods of follow ups to confirm the recurrence rate of the lesion.

Contributors: SA: literature review, manuscript writing and case management; KG, RM: critical review of manuscript and case management; TS, RK: manuscript editing and case management. SA will act as the guarantor. All authors approved the final version of the manuscript.

Funding: None; Competing interests: None stated.

\section{References}

1. Effiom OA, Adeyemo WL, Soyele OO. Focal reactive lesions of the Gingiva: An analysis of 314 cases at a tertiary health institution in Nigeria. Niger Med J. 2011;52:35-40.

2. Shafer, Hine, Levy. Benign and malignant tumors of oral cavity. In: Rajendran R, Shivapathasundaram (Ed) Shafer's Textbook of Oral Pathology. 5th ed. New Delhi, Elsevier: 2007; pp.178-180.

3. Newman, Takei and Klokkevold: Carranza's Clinical Periodontology, $10^{\text {th }}$ ed. W.B. Saunders: 2006; pp. 373387.

4. Greenberg MS, Glick M, Shiip JA. Burket's Oral Medicine- Diagnosis and Treatment, 10th ed, BC Decker Inc Elsevier 2008;179-186.

5. Cotran R, Kumar V, Collins T. Robbins Pathologic Basis of Disease, $6^{\text {th }}$ Edition. W.B. Saunders. 1999.

6. Regezi JA, Sciubba. Connective Tissue Lesions. Oral Pathology: Clinical Pathologic Correlations. $5^{\text {th }}$ ed. St. Louis, Saunders, Elsevier: 2008; pp.155-178.

7. Tyldesley WR. Oral medicine for the dental practitioner. Inflammatory overgrowths and neoplasms. Br Dent J. 1974;136:111-116.

8. Wysocki GP, Gretzinger HA, Laupacis A, Ulan RA, Stiller CR. Fibrous hyperplasia of the gingiva: A side effect of cyclosporine A therapy. Oral Surgery, Oral Medicine, Oral Pathology. 1983;55:274-278.

9. Arvio P, Arvio M, Kero M, Pirinen S, Lukinmaa PL. Overgrowth of oral mucosa and facial skin, a novel feature of aspartyl glucosaminur. J Med Genet. 1999;36:398-404.

10. Borborema-Santos CM, De Castro MM, Dos Santos PJB, Talhari S, Spartaco Astolfi-Filho S. Oral Focal Epithelial Hyperplasia: Report of Five Cases. Braz Dent J. 2006; 17:79-82. 